\title{
Universiteit
}

Leiden

The Netherlands

\section{Lampedusa in Europe; or touching tales of vulnerability}

Minnaard, E.; Boletsi, M.; Houwen, J.J.M.

\section{Citation}

Minnaard, E. (2020). Lampedusa in Europe; or touching tales of vulnerability. In M. Boletsi \& J. J. M. Houwen (Eds.), Palgrave Studies in Globalization, Culture and Society (pp. 145-162). Cham: Palgrave Macmillan. doi:10.1007/978-3-030-36415-1_8

Version: $\quad$ Publisher's Version

License: $\quad$ Licensed under Article 25fa Copyright Act/Law (Amendment Taverne)

Downloaded from: $\quad$ https://hdl.handle.net/1887/3242809

Note: To cite this publication please use the final published version (if applicable). 


\title{
Lampedusa in Europe; Or Touching Tales of Vulnerability
}

\author{
Liesbeth Minnaard
}

The name Lampedusa resonates meaning in multiple ways. Located at the outskirts of Europe and, especially since 2015, place of refuge for a large number of migrants, the Mediterranean island has in recent years not only become a symbol for the so-called European refugee crisis, but also for the dramatic failure of the European Union's border and migration policy as well as for its crisis management. In this chapter I question and oppose the current interpretation of Lampedusa as a worrisome site located in the European

\footnotetext{
I would like to thank Rolf Parr for his hospitality and inspiring enthusiasm during my research stay at the Literature and Media Studies Department of University Duisburg-Essen in May 2019 and Babs Boter (Free University Amsterdam) for her constructive and insightful response to a previous version of this text that I presented at the expert meeting Unbinging the National Framework at Utrecht University in March 2019.
}

L. Minnaard $(\bowtie)$

Department of Film and Literary Studies, Leiden University, Leiden, The Netherlands

e-mail: e.minnaard@hum.leidenuniv.nl

(C) The Author(s) 2020

M. Boletsi et al. (eds.), Languages of Resistance, Transformation, and Futurity in Mediterranean Crisis-Scapes, Palgrave Studies in Globalization, Culture and Society, https://doi.org/10.1007/978-3-030-36415-1_8 
margins. Instead, I argue, Lampedusa should be seen as a heterotopian space at the heart of Europe and read as symptomatic for the European Union's in many respects faltering neoliberal politics. ${ }^{1}$ I will elaborate on this idea by presenting an analysis of the script of the theatre play Lampedusa (2015) by the acclaimed British playwright Anders Lustgarten. ${ }^{2}$ This text, as I will show, simultaneously confirms and subverts the dominant refugee crisis narrative in which Europe struggles to come to terms with the exponentially increased influx of migrants, and it does so in unexpected and thought-provoking ways. ${ }^{3}$ In the following, I will demonstrate how it brings assumedly distinct European crises - the refugee crisis, the financial crisis, the social welfare crisis - together within one interpretative framework, thus prompting readers to think about these crises as what Leslie Adelson (2005) has termed "touching tales"-touching in the sense of emotionally charged tales of insecurity, pain, loss, and fear, but also, importantly, touching in the sense of bordering on each other and interconnected in complex as well as pivotal ways.

As a literary text, Lustgarten's Lampedusa fits in quite neatly with what can be considered a Europe-wide literary trend: the publication of literary works that refer to, imagine, address, and also in more or less activist ways intervene in the dramatic developments at Southern European borders. ${ }^{4} \mathrm{~A}$ new transnational genre of "refugee crisis literature": literature of urgency as Carla Calargé (2015) has called it, illiterature in the term of Hakim Abderrezak (2016), a contemporary form of protest literature or, with an emphasis on the often-intended effect of stirring readers' empathy, literature of concern. These works, including Lampedusa, are mostly written by white European, well-meaning authors who predominantly and in demonstrative opposition to anti-migration populism, take a leftist political standpoint in "refugee crisis" discourse. Very often these politically motivated works support an activist agenda: by more in-depth depictions of refugee protagonists they aim to add nuance and complexity to the rather one-dimensional, objectifying, and often sensationalist representations of refugees in the media, and to "give a voice and restore a lost humanity to the corpses that regularly wash ashore on touristic beaches" (Calargé $2015,3){ }^{5}$

However, despite these good intentions, it seems that only few of these works manage to properly get away from the single refugee crisis story in which refugees, detached from social ties and broader networks, are solely victims and never political subjects, as Ipek Çelik in her monograph In Permanent Crisis argues with regard to European film $(2015,133)$. In the same vein, Agnes Woolley speaks of a strongly normative "narrative 
economy that sets the terms for the enunciation of refugee experience" $(2016,4)$. Following Gillian Whitlock, she points out that the dominant mode of the so-called humanitarian storytelling consists of a mix of human rights discourses and testimonial narrative (Woolley 2016,8). The resulting plot possibilities, so it seems, remain limited: refugee protagonists get a chance to tell their stories of flight and violence, to testify of the horrors that they-in contrast to many others-have survived, but their representation generally fails to escape what Çelik calls "the overarching trope of victimhood" $(2015,127)$. And while "belief in the credibility of the narrative becomes the organizing principle" (Woolley 2016, 8), the reader is not only encouraged to empathize with refugees, but also put in the position of "a 'cosmopolitan,' knowing" judge who is to decide on the authenticity and credibility of the narrative of flight and distant hardship (8-9). ${ }^{6}$

Lustgarten's Lampedusa qualifies in several ways for the generic category outlined above. The play that presents two voices-one male, one female; one Italian, one British-telling us about their experiences "[h]ere, in Europe, 2015" (13), is set in a narrative frame of crisis and appealsdirectly and indirectly-to the reader's concern and commitment. In terms of form the two monologues appear as intersecting narratives of which the first, the story of the Italian fisherman Stefano, a native inhabitant of the island of Lampedusa, seems to tick all the boxes of a conventional "refugee crisis narrative." However, as I will demonstrate in the following close reading of both monologues and of their particular narrative arrangement, it is through this specific intertwinement that Lampedusa resists the more common narrativization of crisis as singular and, instead, draws our attention - both on the level of form and of content - to notions of contact and relation. By doing so, it foregrounds the contested Mediterranean island not as a European outpost that can easily be kept at arm's length, but as closely interlinked to other European spaces that are leaning under the neoliberal strait-jacket.

\section{The Fisherman and His Catch}

In this section I will examine the story that opens the play, and focus especially on the position of its protagonist, Stefano. The stage directions introduce Stefano as follows: "Spotlight on Stefano, alone, reflective. A cigarette burns in his hand. He stares out into the great wide expanse of the Mediterranean Sea" (3; italics in original). Stefano, the Italian fisherman, addresses the reader in the form of a (self-)reflective monologue. In the 
first parts of this monologue, he nostalgically associates himself with the island's long maritime tradition: "My father was a fisherman. And his father before him. And before and before" (7). He aligns himself with a heroic history of Mediterranean crossings by a long list of predecessors: Caesar, Hannibal, the Phoenicians, Carthaginians, Ottomans, and Byzantines. When at sea, he feels as though he follows in their footsteps and becomes part of what, at the beginning of the play, is imagined as the almost-mythical origin of the world: "This is where the world began. ... We all come from the sea and back to the sea we will go. The Mediterranean gave birth to the world" (3). ${ }^{7}$ Stefano imagines himself, pondering, as part of this powerful, vibrant, and life-giving organism. In the play's opening moment, in which he is surrounded by this "giant lung, breathing life into the world" (3) he primarily feels alive. Free. Worriless.

Soon enough, however, this ecstatic moment evaporates and the reassuring feeling of oneness with a motherly and benign Mediterranean dissolves. Reality takes over and the recall of the positive experience of livelihood that the play opens with is replaced by a chilling depiction of death. In continuation of the anthropomorphous image of the Mediterranean as lung, Stefano's detection of "little black spots, floating on its surface" (3) turns the initial image of vitality and vigor into one of illness and disease. These are signs of contagion, spots foreboding death. Simultaneously, for the present-day reader the textual image is uncannily familiar in another register: images of Mediterranean crossings gone astray that since 2015 have saturated the media, frequently showing dead, mostly black migrant bodies floating on the water. And indeed, when Stefano's boat draws closer, the text zooms in on such a tragedy. The subsequent nauseating exposition of the materiality of the numerous corpses that Stefano over the previous period has recovered from the Mediterranean Sea works to draw the reader into the scene and simultaneously has a repulsing effect. Moreover, in this scene the Mediterranean transforms from the powerful, life-giving organism that was evoked at the start of Stefano's reflections into a similarly powerful producer and representative of death. ${ }^{8}$

"The Med is dead" (7), as Stefano sighs some instances later: it contains corpses rather than fish and, as a consequence, also disrupts the professional family lineage that is key to Stefano's identity. For Stefano, as for his ancestors, the Mediterranean determines who he is. The fact that presently, as he suspires, "my job is to fish out a very different harvest" (7) severely affects his self-understanding. On the one hand, it is the substance 
of the harvest, human and lifeless, that disturbs him and causes his nightmares: human beings that are swallowed up by the Mediterranean turned monster. ${ }^{9}$ On the other hand, it is his own uprooted position that worries him: his loss of identity, of grounding in tradition, of self-respect. Dissatisfaction and existential insecurity result from this new situation; holding on and endurance are the preferred solution.

It is through his very personal and in its details often shocking monologue, that Stefano draws the reader into the geopolitical area as well as the ethical, humanitarian problematic that the name Lampedusa has come to represent. The play Lampedusa does not rely on the preferred narrative form of much "refugee crisis literature"-giving a voice to (one of) the migrants-but it puts the testimonial of an involuntary European host at the center of the narrative: the fisherman who reluctantly, as a direct consequence of fundamentally changed circumstances, has turned into a professional rescuer-in lucky instances, that is. More often his job resembles that of a grave digger: he is to clean the Mediterranean of the posthumous remnants of the European Union's current migration politics.

In comparison to works that feature migrant or refugee protagonists and encourage readers to empathize with their tribulations, Lampedusa invites European readers to a form of what Kaja Silverman has called "idiopathic identification": ${ }^{10}$ for the average European reader it is easier to share in Stefano's feelings of alienation and concern than to identify with a story of flight and illegality. Even if most readers of this British theatretext probably reside in parts of Europe that are further removed from its aquatic border to the Global South than Stefano, they will recognize the dilemma that he is confronted with. The tension in Stefano's narrative between his "guilty" humanitarian conscience on the one hand, and his worries about (the impact of this crisis for) his own existence on the other hand, is a tension that is central to refugee crisis rhetoric Europe-wide. A decisive point of difference between the reader and Stefano, however, besides their ontological status, is that the latter is actually doing the dirty work. As Stefano himself is well aware, he is doing " $[\mathrm{t}]$ he job no-one else will take" (Lustgarten 2015, 7).

Lampedusa's Stefano is a simple fisherman, wrestling to survive in an incommensurably less dangerous, yet on a personal level just as disruptive context of crisis as that of the migrants and migrant bodies he is "catching." In this sense, Stefano can be seen as representative of a working class, located especially in the European south, that has great difficulties to make ends meet in today's globalized economy. In a context in which 
EU-austerity politics has tended to cast the Southern European working class, if not its professional population as a whole, as either lazy profiteers or as superfluous and dispensable to the (global) economic machine, ${ }^{11}$ Lampedusa offers its readers insight in the precarious, split situation in which one of these Europeans finds himself. In his monologue Stefano shares his particular worries, his fears, his nightmares, his feelings of vulnerability. But he also shares, in his capacity as what Tim Cresswell has called an "everyday theorist" $(2007,79)$, his analysis of the Lampedusa situation of crisis. He calls the refugee center on the island embarrassing: "[1]ooks like Guantanamo" and "makes us look cruel and closed" (Lustgarten 2015,8$)$. "[B]ut" he asks, in a rhetorical question to the reader: "where else can we put 'em?" (8), and extrapolating from there, "where is everybody else? Why are we, a little dusty island you've never heard of, left to deal with all this alone?" (9). It is rhetorical questions like these, combined with Stefano's negative assessments of the state of Italy in particular-“In Italy there's no hope" (9)-and of Europe more in general- "[D]o the migrants not understand Europe is fucked?" (9)- that point the reader to a problematics of crisis that reaches way further than just Stefano's personal situation on the island of Lampedusa. Lampedusa is not only in Europe, Lampedusa is Europe.

What appears as central in Stefano's assessment of this broader situation of crisis is the complete absence of support that he experiences: not only by the European Union and the (in Stefano's opinion corrupt) Italian state, but, importantly so, also the support provided by solidarity, by community, by intersubjective relations. In the world that he sketches in his monologue it is every man for himself and even more negative than that: "Here, in Europe, 2015. You have to watch yer back from every angle" (13). In the specific moment in the text in which Stefano makes this claim, it actually concerns the risk that newcomers, such as the ones he tries to save from drowning, will make him superfluous, his labour redundant. That they will take his job, do it better and for only half the wage that he would need to make a living. At the same time, his addition "here, in Europe," as well as the fact that the refugee who triggers this thought, the Malian Modibo, becomes a very close friend despite Stefano's initial rejection - the only one, so he feels, who understands him and his psychological struggles (22)—work to expand the scope of the claim: the stated necessity to always be on guard and the more general sense of unsafety that the claim puts forward are indicative of the contemporary status quo of living, or rather surviving in neoliberal times. The juxtaposition between 
Stefano's "everyday analysis" and an even stronger skepticism about "Europe" and the home it provides in Lampedusa's second parallel monologue, further reinforces this impression of thorough existential insecurity.

It is the rather stereotypically depicted character of Modibo-optimistic, always smiling, never complaining-who plays an important role in Stefano's subsequent transformation from a bitter skeptic who has lost the lust for life into a life-embracing character, grateful for the lesson of hope, melodramatic as this may sound, that his relation with Modibo has taught him. Modibo is the character in Lampedusa that, quite in tune with "refugee crisis literature" conventions, gives a human face to the threatening migrant mob that is supposedly invading Europe. Simultaneously, this character functions as a catalyst in Stefano's reconciliation with his precarious situation. From the start of his monologue the expression of mistrust and rejection that Stefano feels towards the migrants is interwoven with moments of self-reflection. Thinking back to one of his professional encounters with migrants at sea, he recalls:

You try to keep them at arm's length. If you let them get close, you never know what they might ask for. On the boat the survivors start talking to me, pleading their case, like I can do anything for them.

It's not part of my job to listen to their stories.

There's too many of them.

And it makes you think.

About the randomness of I get to walk these streets and he doesn't.

You start thinking about things like that, the ground becomes ocean under your feet. (13)

As the above passage wonderfully demonstrates, Stefano's thoughts oscillate wildly from feelings of helplessness to a rejection of responsibility and, again, from a sense of powerlessness - in a situation out of control- to a reflection on the arbitrary facts of life more in general. His intention to keep a distance and to not listen to these survivors rapidly slides into a reflection on his own privileged as well as random position, a relativizing reflection that testifies of exactly the listening that is "not part of [his] job" (13). His mind moves from "There's too many of them" and the fear of large numbers to the very slippery question of "why not me?"- a question better kept at bay in order not to drown in an ocean of existential doubt.

Interestingly, the " $[\mathrm{t}]$ here's too many of them" also resonates meaning in quite a different, if not opposed sense in a later moment in the script. 
There Stefano reflects on the traditional, masculinist stance fishermen are supposed to take when confronted with casualties at sea:

We're fishermen and fishermen die. You're not supposed to make a big deal of death, you mourn and you get back to life while you've still got it. But there's never been a time when three hundred and fifty have died at once. In sight of shore. With no-one to mourn for them. (22)

Again, on the one hand, Stefano is struggling not to be affected, to perceive of these casualties as the "collateral damage" of a migration politics that is framed as inevitable self-defense; on the other hand, he has great difficulties to come to terms with the underlying suggestion that these lives do not matter. Current EU-legislation stipulates these non-European, non-white, and dispossessed individuals' attempts to enter Europe as illegal. ${ }^{12}$ Stefano struggles with what seems to be the disturbing consequence of this judicial decision: that the lives of the thus criminalized, of the corpses that he catches-human remnants of illegalized crossings-actually, judicially seen, do not deserve to be mourned.

Lampedusa's first narrative thus sketches the transformation of a "common" European citizen, worried about his existence and about the threat posed by the arrival of large numbers of "fortune hunters," to an individual who comes to care and feel hope through his encounter with one of these illegalized migrants. As already mentioned, this narrative does not escape the pitfalls that haunt the refugee crisis genre. A certain romanticization of the fisherman turned rescuer, the spectacular quality of the recovering of the dead, the centrality of the white men's conscience and, last but not least, the exoticization of the African Modibo as a catalysing figure in Stefano's transformation and as a carrier of hope: these elements together lend the story an at times clichéd if not downright problematic character. Moreover, Stefano's change of attitude towards refugees within the narrative seems rather predictable, and the climax (Stefano in an act of reckless heroism rescues Modibo's wife from drowning) as well as the ending ("They've given us joy. And hope ... And I thank them for that" [33]) appear over the top in their strong melodramatic make-up. However, as I will argue in the following section, the assessment of Lampedusa's critical impact changes when one considers the larger picture that the juxtaposition of the two parallel stories provides. By focusing on the specific 
combination of Stefano's quite conventional and melodramatic refugee crisis-story with the monologue of its second protagonist, Lampedusa's original and thought-triggering contribution to refugee crisis discourse becomes clear. As I will demonstrate, the critical force of Lampedusa's intervention hinges exactly on this strategy of juxtaposition-on the way in which it encourages us, readers, to think about the relation between two European stories of crisis that at first sight appear utterly apart.

\section{The Debt Collector and Her Dream}

Central to the second narrative that Lampedusa presents us with, is the character of Denise, a working class female of mixed British-Asian descent located in the north of England. In terms of form, her story is closely intertwined with that of Stefano: fifteen times during the play the stage lights go down on Stefano in order to go up on Denise and vice versa. Denise's first introduction in the stage directions, immediately after Stefano's dramatic reflections on the fundamentally changed conditions of his profession, provides an apt characterization of her suspicious posture: "Lights up on Denise, mixed white and East Asian, cautious, observant. She watches us" (Lustgarten 2015, 5). Denise, as soon becomes clear, is full of mistrust and always on guard. Her reservation towards others includes the readers: in a world where people primarily look after themselves, no one is to be trusted, an attitude grown from Denise's everyday experiences in contemporary England.

Denise in many ways qualifies as the ideal neoliberal citizen that demonstrates resilience, flexibility, endurance, and a hyper-rational mindset, especially in times of crisis. ${ }^{13}$ She excels in everyday strategies of survival in a context determined by economic austerity and a redressal of the social welfare system. Her most important strategy, so she makes it seem, is assuring she cannot be hurt, bracing herself, in any case not showing (or admitting) her vulnerability. The social behavior that she demonstrates in relation to the characters around her and that she advocates towards the reader who she regularly draws into her argument by means of direct address_- "let me tell you that" (11) - is to be harsh, not to care and, in the first place, to look after yourself. All this is a manifestation of her shock-proof neoliberal resilience that enables her to withstand socioeconomic hardship and to secure her financial and emotional independence. 
In her monologue, Denise sketches a bleak image of contemporary England, northern England (East Yorkshire) in particular:

I can't stand this country now.

The hatred.

The hatred and the bitterness and the rage. The misplaced, thick, ignorant rage. (11)

She describes British society as a hostile place and as a social desert where especially people in the margins try to survive their new poverty-a result of severe cutbacks in social welfare provisions-by keeping up appearances and scapegoating others. She herself surely uses this same strategy. As a debt collector, working for the loan company ATOS-another job no-one else will take-her task is to cash from people who neither have money nor income. Moreover, and not unrelated to their economic position, they are without prospect, social network, and often in poor health. Despite the fact that Denise clearly deals with people in precarious positions that are, except for the employment, not so different from her own, she despises their dependence on the social welfare system as well as the vulnerability that ensues from their situation. From her monologue it becomes clear that she herself has always been an outcast, an outcast among the "lowly." Especially her mixed race functioned as a marker of difference and, supposedly, inferiority, and continues to do so on a daily basis: all feelings of frustration and helplessness that her ATOS-clients experience seem to find a way out in the form of verbal, often racist violence, targeted at Denise. She, in a reversal of this daily offence, holds on to, or rather insists on, the difference between her and her dispossessed clients: "Learn some discipline. If you ant got the money, do without. / I have. I do." (7).

In Lampedusa, Denise's assumption of an assumedly protective neoliberal mindset is put to a test when her aged mother, whom she describes as a traumatizing, loveless factor in her life, becomes fully dependent on social welfare. She qualifies as "a proper case," Denise assures in her monologue, "not like most of these I deal with" (15). It is in Denise's account of her mother's destitute situation that the dehumanizing workings of the production-and-profit-centered neoliberal system become clear. Simultaneously, her mother's miserable situation constitutes Denise's drive to search for ways out of this lonely, poverty-ridden margin. And while her chances, arguably, are low, Denise not only dreams of escape but 
also invests her spare time and money in studies and in the promise of upward mobility that education represents for her:

[I]f the results [of the exams] are good enough, I can go anywhere.

Australia. America.

China even. Doing well, ent they? That'd be fucking ironic.

Anywhere but here.

Slam the door on this bitter washed up country, turn me back, be free. I don't know what free is, where I'll find it, but that is where I am going and nobody will stop me. (12)

Her dream of escape, including escape from the racism she has been confronted with all her life, is very much framed in individualistic terms: rather than forming a fantasy about changing her present circumstances, she longs for gaining individual freedom elsewhere. In her here and now, so hegemonic neoliberal discourse has taught her, there is no alternative. Hence Denise imagines an alternative future elsewhere. Whether this dream can be categorized as a form of "cruel optimism," as described by Lauren Berlant (2011), or as an indicator of the skills and courage to think otherwise and, as such, to resist her situation, is debatable. Does it testify of what Sarah Bracke describes as "the kind of agency an ethos of resilience forecloses: . . . the developing of skills of imagining otherwise" (Bracke 2016, 63) or of "a relation of attachment to compromised conditions of possibility" (Berlant 2006, 21), to a fantasy of "the good life" that is in the current circumstances fraying, dissolving, even cruel? ${ }^{14}$

In Lampedusa's monologue it is, again, intersubjectivity that steers the narrative in a different direction, away from slamming the door and turning away. Like Stefano in the first narrative, Denise meets someone-again a stranger, an ATOS-client: the Spanish single mother Carolina-who is sincerely and unconditionally kind to her: "no agenda, just nice" (17). The impact of the repeated instances of intersubjectivity and gestures of care is enormous. Whereas Denise first, unbelievingly, feels taken off guard, her suspicion abates when she realizes that these are actually acts of kindness outside of the capitalist economy of profit and exchange. And although a certain amount of exoticism and melodrama arguably also undermines the critical effect of this second narrative, the message of hope- "hippy shit but fuck it" (32) -with which Denise concludes her monologue is critically moving, especially in combination with her newborn recognition that "attachment is crucial to survival” (Butler 2004, 45). 


\section{Intersecting Narratives, Touching Tales}

In this last section I will now bring the two analyses together and point out how the juxtaposition of the two narratives even deepens each monologue's critique of the neoliberal ethos of individualism and resilience that reigns all over Europe and, moreover, poses a critical counterpoise to dominant crisis rhetoric with its emphasis on singular and separate crises. In terms of plot, the two narratives never touch and despite the formal suggestion of a dialogue - the alternating voices appear as if they are speaking to each other-Stefano and Denise live in completely separate worlds. There is no attempt in the text to bring the two characters together, except for one moment at the very end of the text, in the stage directions; a meaningful moment to which I will come back later. However, despite the fact that there is no explicit order that suggests a comparison of Stefano's and Denise's stories, as a reader you are encouraged to think them together, purely on the basis of their joint appearance in the play, on the basis of their parallelization. And this is as interesting as it is important.

In Lampedusa the story of the refugee crisis as told by the Italian fisherman Stefano and the story of the social welfare crisis as told by the British debt collector Denise appear as "touching tales." Leslie Adelson coined this phrase in her monograph The Turkish Turn in Contemporary German Literature (2005) in which she insightfully pleads for a new critical grammar for studying migration in its intersection with other events in history. Adelson proposes the concept of touching tales to explore how, in German literature, the history of labor migration and that of the Holocaust- two histories that are traditionally considered distinct from each other"touch"; how they resonate affect and meaning in relation to each other. She defines touching tales as "literary narratives that commingle cultural developments and historical references generally not thought to belong together in any proper sense" (Adelson 2005, 20). Defined as such, the term resonates with several other theories and concepts that aim to think historical narratives together that have conventionally been kept apart, such as Mary Louise Pratt's notion of contact-narratives (1992), Andreas Huyssen's study of forms of triangulation (1995), and Michael Rothberg's concept of multidirectionality (2009). The specific surplus value of the idea of touching tales lies in the double meaning of the term "touching" that not only denotes the close proximity of the two tales brought together in one narrative, sharing the pages of one book, but also hints at the affective, touching dimension of their touching. 
What does it mean now, when I contend that the refugee crisis and the social welfare crisis appear as touching tales in Lustgarten's Lampedusa? In what ways do they touch, and to what effect? In my opinion these are questions that the literary text assigns to the reader who is to make sense of the-in plot-terms unmotivated-juxtaposition of two stories of contemporary precarity, as well as, as I would now like to argue, resistance.

In its representation of Stefano's and Denise's daily tribulations, Lustgarten's Lampedusa points at a general, widespread pattern of precarity that is, at least partly, the result of the European Union's neoliberal, technocratic politics and the faltering social infrastructure that this politics has entailed. When Stefano sighs "do the migrants not understand Europe is fucked?" (Lustgarten 2015,9) and, more (melo)dramatically, "I resent them for their hope" (9), he evokes an image of a harsh and inhospitable Europe. This Europe is not only an inhospitable place for illegalized migrants and refugees, but also for its legal inhabitants; an image that matches quite well with Denise's perception of a socially bleak UK. It is in this sense that Lampedusa very much imagines "the present moment . . . as a moment in extended crisis," as described by Lauren Berlant, in which "conventions of reciprocity that ground how to live and imagine life are becoming undone" $(2011,7)$ and "in which people find themselves developing skills for adjusting to newly proliferating pressures to scramble for modes of living on" (8). In Vulnerability in Resistance Judith Butler argues that the neoliberalism that produces this precarious present, the "crisis ordinary" in Berlant's terms, tends to establish the individuals that it leaves dispossessed and disenfranchised-such as Stefano, Denise, as well as the migrants-as "vulnerable populations" (Butler et al. 2016, 25). But rather than a call for care and action, this attribution of vulnerability as an identity-marker fixes the subjects constituted by the term "in a political position of powerlessness and lack of agency" (25). Lampedusa challenges this fixation as much as it challenges the neoliberal promotion of an ethos of resilience. By presenting two narratives of precarity in which intersubjectivity and acts of kindness open up a more expectant, forward-looking attitude towards life as well as a heartening sense of community, it questions the neoliberal ideal of individual endurance and of an endless bouncing back.

I consider the revealing of this Europe-wide precarity, an outcome of various interlocking crises that in themselves can be understood as the result of deficient neoliberal policies, as Lampedusa's first achievement. Undoing the above-mentioned reified definition of vulnerability as a 
position of powerlessness and passivity is a second. As EU-subjects in vulnerable positions, trying to survive in the socio-economic margins of the European Union, Stefano and Denise seem to have no other choice than to adapt to, and even perform, the neoliberal policies from which they themselves do not gain or profit in any way. Through the performance of their particular jobs, jobs that no-one wants, they-involuntarily-turn into the everyday representatives and even executers of the neoliberal system. As minor Europeans they give a face to laws and policies made elsewhere, while simultaneously facing and dealing with their dehumanizing consequences. However, and this is important, in Lampedusa the protagonists' vulnerability neither automatically effaces their agency, nor their capacity to resist. In both stories, the key to resistance is intersubjectivity. It is through small and unexpected acts of kindness-personal and, as such, in stark contrast to the anonymizing technocratic system - that both Stefano and Denise come to realize that they are not only exposed, but can also relate and be of value to others, a realization that has an empowering effect on their resilient, but isolated subjectivities. ${ }^{15}$ From the perspective of EU-politics, their resistance-small instances of caring in the margins of the margin - may seem futile and have little to no effect on the larger status quo, but the impact on the characters' self-perception is immense and life-changing. The discovery and subsequent acknowledgement of their relation(ality) to others not only has a self-affirmative effect, but also motivates them to think of themselves as part of a community of hope.

\section{Conclusion}

In its representation of two EU citizens struggling to survive in the European societal margins, Lampedusa does not deny these subjects' vulnerability. On the contrary it empathically shows them in their precarious situations: struggling to tread water. But, in doing so, Lampedusa does not settle for the association of vulnerability with a lack of political agency. It is by locating change and hope in small but impactful moments of intersubjectivity, melodramatic as they may appear, that Lampedusa criticizes and breaks away from the idealization of an ethos of resilience within a strategically individualized neoliberal ideology.

This happens within the stories that Stefano and Denise tell us about their lives, but it also takes place outside of these narratives on the level of narration. Right after Stefano's concluding words "I defy you" (Lustgarten 2015,33 ), I defy you to feel hope as well, addressed directly to the reader, 
the final stage directions prescribe the first and only moment of contact between Stefano and Denise: "Stefano and Denise look warily at one another" (33). While the use of the term "warily" clearly indicates the hesitant and cautious character of this exchange of glances that concludes and undoes the parallelization of Stefano's and Denise's existences, this intersubjective moment very much takes place under the sign of the prior appeal to feel hope and of the impactful moments of contact between Stefano and Modibo, and between Denise and Carolina. And while Stefano and Denise, all the time together on stage, for the first time look at each other, see each other, the reader becomes part of this concluding as well as opening scene of intersubjective intimacy.

\section{Notes}

1. I am well aware of the multiple and contested meanings of the term neoliberalism, as a.o. described by Damien Cahill et al. in The Sage Handbook of Neoliberalism (2018). In this chapter I consider neoliberalism as the hegemonic political doctrine in contemporary Europe that entails a mode of liberal governance that prioritizes free market and economic growth and that emphasizes consumer citizenship, personal responsibility, and individual empowerment. See Van Weyenberg (2016) for a critical discussion of the center/periphery binary in the EU's attempted construction of a "shared" narrative of Europe.

2. This chapter chooses to read the script of Lampedusa as a literary text and focuses on its politics of literary representation and on the way in which the dramatic text addresses its readers. The play was first performed in the Soho Theatre in London in 2014 and has been successful ever since with performances all over Europe, including Germany, Malta, and Greece. Each of these performances provides a different, often strongly site-specific interpretation of the dramatic text.

3. As many scholars have pointed out, refugee crisis rhetoric represents migrants and refugees either as powerless victims, in need of help, or criminalizes them as public welfare abusers and even terrorists (Bauman 2016, Wienand and Minnaard 2019, Žižek 2016). Scholars also emphasize the strong politicization of the terminology used for people trying to cross the Mediterranean "illegally" (Carasthatis et al. 2018, De Genova and Tazzioli 2016).

4. A similar trend can be distinguished in the field of film. See, for instance, Bennett 2018 and Rangan 2017.

5. In Contemporary Asylum Narratives: Representing Refugees in the TwentyFirst Century, Agnes Woolley warns that "representations cloud as much as 
they clarify" and states that the "tension between occlusion and revelation is most ethically and politically pressing in relation to disenfranchised groups who have only limited access to the means of self-representation" $(2014,3)$.

6. For a thorough reflection on empathic identification in respect to artistic representations of refugee experiences see Houwen 2016.

7. This idea resonates in interesting ways with Iain Chambers' notion of the Mediterranean as a postcolonial sea (2004).

8. Although the Mediterranean appears as the monstrous producer of death here, the association of refugees themselves with contagion and illness"carrier[s] of a disease called "crisis" (De Genova et al. 2016, 20)—is activated here as well. As De Genova et al. write: "Some of these embodiments of 'crisis' are literally converted into figures of death as the corpses of migrants and refugees become spectacularly visible through the proliferation of images of dead bodies floating in the sea or washing upon the shores of "Europe"” (20).

9. In a later, major dramatic moment in Stefano's monologue, this image of the Mediterranean as monstrous returns: "Leviathan looms. A monstrous wave as tall as a tower block, so tall it has little waterfalls tumbling from its crest. ... A roar, and it slams us under its paw and the whole boat goes under" $(26 / 27)$. The two fishermen in this scene, Stefano and his compagnon, survive, but on the surface of this cannibalistic Mediterranean they detect "[ $t]$ he black silhouettes of corpses" (28), the monster's prey.

10. Kaja Silverman (1996) makes a distinction between idiopathic and heteropathic identification. The first form relies on a certain (projected) likeness between the other and the self, whereas the latter involves a more risky, but as Ernst van Alphen argues also more "affectively powerful" $(2008,28)$, temporary and partially becoming like the other.

11. Cf. Boletsi 2018.

12. Cf. De Genova 2018.

13. Mark Neocleous states that " $[\mathrm{r}]$ esilience comes to form the basis of subjectively dealing with the uncertainty and instability of contemporary capitalism as well as the insecurity of the national security state ... Neoliberal citizenship is nothing if not a training in resilience as the new technology of the self: a training to withstand whatever crisis capital undergoes and whatever political measures the state carries out to save it" $(2013,5)$. See also Bracke 2016. The factors of race and gender are also determinant of Denise's position and point at the intricate intersection of neoliberalism with postfeminism, as described by Jess Butler (2013).

14. Both Stefano's and Denise's monologues, about "navigating what's overwhelming" in a situation of "impasse induced by crisis" (Berlant 2011, 10), fit Berlant's interpretive framework of "cruel optimism" exceptionally 
well: their stories "are about the cruelty of optimism for people without control over the material conditions of their lives and whose relation of fantasy is all that protects them from being destroyed by other people and the nation." $(2006,33)$.

15. These narrative developments very much resonate with Judith Butler's idea that "imagining community affirms relationality not only as a descriptive or historical fact of our formation, but also as an ongoing normative dimension of our social and political lives, one in which we are compelled to take stock of our interdependence" $(2004,27)$.

\section{Works Cited}

Abderrezak, Hakim. 2016. Ex-Centric Migrations. In Europe and the Maghreb in Mediterranean Cinema, Literature, and Music. Bloomington: Indiana University Press.

Adelson, Leslie A. 2005. The Turkish Turn in Contemporary German Literature: Toward a New Critical Grammar of Migration. New York: Palgrave Macmillan. van Alphen, Ernst. 2008. Affective Operations of Art and Literature. RES 53 (54): 21-30.

Bauman, Zygmunt. 2016. Strangers at Our Door. Cambridge: Polity Press.

Bennett, Bruce. 2018. Becoming Refugees: Exodus and Contemporary Mediations of the Refugee Crisis. Transnational Cinemas 9 (1): 13-30.

Berlant, Lauren. 2006. Cruel Optimism. Differences: Journal of Feminist Cultural Studies 17 (3): 20-36.

- 2011. Cruel Optimism. Durham; London: Duke University Press.

Boletsi, Maria. 2018. The Futurity of Things Past: Thinking Greece beyond Crisis. Inaugural Speech as Marilena Laskaridis Chair of Modern Greek Studies, Amsterdam, Netherlands, 21 September 2018. University of Amsterdam.

Bracke, Sarah. 2016. Bouncing Back. Vulnerability and Resistance in Times of Resilience. In Vulnerability in Resistance, ed. Judith Butler, Zeynep Gambetti, and Leticia Sabsay, 52-75. Durham; London: Duke University Press.

Butler, Judith. 2004. Precarious Life. The Powers of Mourning and Violence. London; New York: Verso.

Butler, Jess. 2013. For White Girls Only? Postfeminism and the Politics of Inclusion. Feminist Formations 25 (1): 35-58.

Butler, Judith, Zeynep Gambetti, and Leticia Sabsay, eds. 2016. Vulnerability in Resistance. Durham: Duke University Press.

Cahill, Damien, Melinda Cooper, Martijn Konings, and David Primrose, eds. 2018. The SAGE Handbook of Neoliberalism. London: Sage.

Calargé, Carla. 2015. Clandestine or Conquistadores? Beyond Sensational Headlines, or a Literature of Urgency. Research in African Literatures 46 (2): $1-14$. 
Carastathis, Anna, Natalie Kouri-Towe, Gada Mahrouse, and Leila Whitley. 2018. Introduction. Refuge: Canada's Journal on Refugees 34 (1): 3-15.

Çelik, Ipek A. 2015. In Permanent Crisis. Ethnicity in Contemporary European Media and Cinema. Ann Arbor: University of Michigan Press.

Chambers, Iain. 2004. The Mediterranean. A Postcolonial Sea. Third Text 18 (5): 423-433.

Cresswell, Tim. 2007. Place. A Short Introduction. Malden; Oxford: Blackwell.

De Genova, Nicolas. 2018. The 'Migrant Crisis' as Racial Crisis: Do Black Lives Matter in Europe? Ethnic and Racial Studies 41 (10): 1765-1782.

De Genova, Nicholas and Martine Tazzioli, eds. 2016. Europe/Crisis: New Keywords of 'the Crisis' in and of 'Europe.' Zone Books Online. http://nearfuturesonline.org/europecrisis-new-keywords-of-crisis-in-and-ofeurope/. Accessed August 22, 2019.

Houwen, Janna. 2016. An Empty Table and an Empty Boat: Empathic Encounters with Refugee Experiences in Intermedial Installation Art. American, British and Canadian Studies 27 (1): 44-73.

Huyssen, Andreas. 1995. Twilight Memories. Marking Time in a Culture of Amnesia. New York; London: Routledge.

Lustgarten, Anders. 2015. Lampedusa. London: Bloomsbury Methuen Drama.

Neocleous, Mark. 2013. Resisting Resilience. Radical Philosophy 178 (March/ April): 2-7.

Pratt, Mary Louise. 1992. Imperial Eyes. Travel Writing and Transculturation. London; New York: Routledge.

Rangan, Pooja. 2017. Immediations: The Humanitarian Impulse in Documentary. Durham; London: Duke University Press.

Rothberg, Michael. 2009. Multidirectional Memory. Remembering the Holocaust in the Age of Decolonization. Stanford: Stanford University Press.

Silverman, Kaja. 1996. The Threshold of the Visible World. New York: Routledge.

Van Weyenberg, Astrid. 2016. 'Repairing Europe': A Critical Reading of Storytelling in European Cultural Projects. In Peripheral Visions in the Globalizing Present. Space, Mobility, Aesthetics, ed. Esther Peeren, Hanneke Stuit, and Astrid Van Weyenberg, 164-181. Amsterdam; Leiden: Brill Rodopi.

Wienand, Kea, and Liesbeth Minnaard. 2019. Introduction: Taking Positions on the 'Refugee Crisis': Critical Responses in Art and Literature. FKW//Zeitschrift für Geschlechterforschung und visuelle Kultur 66 (September): 17-26.

Woolley, Agnes. 2014. Contemporary Asylum Narratives: Representing Refugees in the Twenty-First Century. Basingstoke: Palgrave Macmillan.

- 2016. Narrating the 'Asylum Story': Between Literary and Legal Storytelling. Interventions. International Journal of Postcolonial Studies 19 (3): 1-19.

Žižek, Slavoj. 2016. Against the Double Blackmail. Refugees, Terror and Other Troubles with the Neighbours. London: Penguin. 